\title{
Seismic Evaluation of RC Framed Irregular Buildings with Soil Structure Interaction
}

\author{
Mamathashree K.S ${ }^{1}$, Sanjay S.J ${ }^{2}$ \\ ${ }^{1}$ PG Student, Department of Civil Engineering, BGS Institute of Technology, B G Nagar, Karnataka, India \\ ${ }^{2}$ Assistant professor, Department of Civil Engineering, BGS Institute of Technology, B G Nagar, Karnataka, India
}

\begin{abstract}
Effect of irregularity and soil structure interaction are the prominent factors for the mega structures resting on highly flexible soil. In the conventional design process effect of soil structure interaction is neglected, as the flexibility of soil increases natural period also increases which intern reduces the base shear. In this paper studied the seismic response of RC special moment resisting frame buildings of 4,8,12 storeys regular and irregular structure resting on different types of soil, by linear response spectrum analysis with and without soil structure interaction effect and also found the seismic behavior of mass, stiffness, diaphragm and reentrant corner irregular buildings with the inclusion of soil structure interaction. Seismic response of these buildings in terms of base shear, maximum displacement, natural period, are found and variations of these with building height, type of soil, inclusion of soil interaction by Winkler method are found. Effect of soil structure interaction on regular and irregular buildings with different soil types are also examined. Consideration of irregularity and soil structure interacton effect both reduces the stiffness of structure hence the structure becomes more flexible due to this natural period increase. From the design consideration change in natural period due to irregularity and soil structure interaction is an important issue.
\end{abstract}

Keywords: Irregular buildings; Soil structure interaction (SSI); Spring stiffness; Flexibility; Dynamic analysis

\section{Introduction}

Industrialization is the main cause of urbanization, in all countries due to this the migration of people to urban centers has rapidly increased, the land available to accommodate this migration is sporadic.Due to local topographical restrictions and increase in urban population lead to the development of multistoried buildings, these are the best solution developed by developers to full fill the residential needs and these are utilized for multipurpose activities apart from this the saftier design of these multistory buildings is necessary to withstand safely in its life time. One of the most devastating natural hazard is earthquake this can cause great loss of life and livelihood. The losses occur directly or indirectly from earthquakes, most losses occur due to collapse and damage of buildings.To resist moderate and severe earthquake ground motions it is very important to design the structure, retrofitting is important if existing buildings are not designed for earthquake.

In the earthquake engineering soil structure interaction is a special field of analysis. A process in which the response of structure is influenced, by flexibility of soil and the soil response is influenced by the presence of structures is

defined as soil structure interaction. Due to damages caused by earthquakes in recent researches pointed out that, during earthquakes structural behavior not only depend on the response of super structure also depends on the response of the sub soil and foundation of the structures. While determining structural behaviors it is necessary to incorporate the effect of soil structure interaction.

Recent days another major problem of structure is its irregularity due to aesthetical, architectural purposes these are unavoidable in construction, so adequate precaution should be taken while designing the irregular building to resist earthquakes.

\section{Literature Survey}

Dr. Ragavendra singh et al., (2014) [1] Studied the effect of vertical irregularity on the seismic response of building.in any structure weakness arises due to irregularity, irregularity is nothing but discontinuity of mass, stiffness and geometry of structure. Irregularity in any structure causes failure during earthquake.in this paper they studied the effect of vertical irregularity on seismic response of ordinary moment resisting frame building with and without shear wall for different zones.In this study variation of Parameters like storey drift and lateral displacements were discussed.

R M Jenifer Priyanka et al., (2012)[2] Studied the seismic behavior of multistory RCC building with rigid and flexible base under different soil conditions. Response spectrum analysis is carried out by STADD Pro software package by assigning soil stiffness to the base of the building for flexible condition. Response of frames such as axial force, base shear, storey drift, column moments, are studied for both rigid and flexible foundation under different soil conditions. They conclude that due to realistic estimation of forces in flexible foundation, the suitable foundation should be adopted is flexible foundation system in seismic design of building.

Koushik Bhattacharya et al., (2006)[3] Studied neglecting the effect of soil structure interaction in the design of low rise building resting on raft foundation, neglecting these effects cause unsafe seismic design. In this paper studied the effect of flexibility of soil by dynamic analysis with varying number of storeys, bays etc... are computed. Various parameters like base shear, torsional to lateral period ratios for low rise building resting on mat and isolated footing with the effect of SSI are estimated by elastic domain in comprehensive manner. For the easy and convenience of

Volume 5 Issue 6, June 2016 www.ijsr.net 


\section{International Journal of Science and Research (IJSR) \\ ISSN (Online): 2319-7064}

Index Copernicus Value (2013): 6.14 | Impact Factor (2015): 6.391

seismic design process in this paper a number curves are formed to show the variation of these two parameters and to evaluate the effect of SSI for the designers.

\section{Modelling and analysis}

\subsection{Substructure modelling}

\subsubsection{Soil properties}

Effect of soil flexibility under different soil types is studied in this paper. The value of shear modulus [G] for different soil types can be found by

$$
\mathrm{G}=\mathrm{Vs}^{2} \mathrm{X} \rho
$$

Shear wave velocity is estimated from the following expression

$$
\mathrm{Vs}=\sqrt{(E s /(2 \times \rho \times(1+v))}
$$

Table 3.1: Details of Soil Parameters (Ref J E Bowls)

\begin{tabular}{|c|c|c|c|c|c|c|c|}
\hline Soil type & $\mathbf{v}$ & $\begin{array}{c}\mathbf{E s} \\
\mathbf{M P a}\end{array}$ & $\begin{array}{c}\mathbf{P} \\
\mathbf{K g} / \mathbf{m}^{3}\end{array}$ & $\begin{array}{c}\mathbf{V s} \\
\mathbf{m} / \mathbf{s e c}\end{array}$ & $\begin{array}{c}\mathbf{S B C} \\
\mathbf{K N} / \mathbf{m}^{2}\end{array}$ & $\mathbf{D}$ & $\begin{array}{c}\mathbf{G} \\
\mathbf{K N} / \mathbf{m}^{2}\end{array}$ \\
\hline $\begin{array}{c}\text { Hard } \\
\text { (Gravel) }\end{array}$ & 0.25 & 64 & 2100 & 110 & 440 & $1.5 \mathrm{~m}$ & 25410 \\
\hline $\begin{array}{c}\text { Medium } \\
\text { (Medium sand) }\end{array}$ & 0.35 & 33 & 1900 & 80 & 245 & $1.5 \mathrm{~m}$ & 12160 \\
\hline $\begin{array}{c}\text { Soft } \\
\text { (Moist clay) }\end{array}$ & 0.45 & 12.5 & 1700 & 50 & 150 & $1.5 \mathrm{~m}$ & 4250 \\
\hline
\end{tabular}

Where $\mathrm{v}=$ Poissons Ratio

$\rho=$ Mass density, in $\mathrm{Kg} / \mathrm{m}^{3}$

Es=Modulus of elasticity, in MPa

$\mathrm{Vs}=$ Shear wave velocity, in $\mathrm{m} / \mathrm{sec}$

$\mathrm{G}=$ Shear modulus, in $\mathrm{KN} / \mathrm{m}^{2}$

$\mathrm{D}=$ Depth of footing, in $\mathrm{m}$

$\mathrm{SBC}=$ Safe bearing capacity of soil, in $\mathrm{KN} / \mathrm{m}^{2}$

\subsubsection{Static stiffness of equivalent soil springs along} various degrees of freedom

Spring constants calculated by Winkler idealization formulas for stiffness of rigid embedment foundations which are shown in below tables.

\begin{tabular}{|c|c|}
\hline Degrees of freedom & Equivalent spring stiffness of soil \\
\hline vertical & {$[2 \mathrm{GL} /(1 \mathrm{v})]\left(0.73+1.5 \mathrm{X}^{0.73}\right)$ withX $=\mathrm{A}_{\mathrm{f}} / 4 \mathrm{~L}^{2}$} \\
\hline Horizontal(lateral direction) & {$[2 \mathrm{GL} /(2-\mathrm{v})]\left(2+2.5 \mathrm{X}^{0.55}\right)$ withX $=\mathrm{A}_{5} / 4 \mathrm{~L}^{2}$} \\
\hline Horizontal(Iongitudinal direction) & {$[2 \mathrm{GL}(2-\mathrm{v})](2+2.5 \times 0.85)-[0.2(0.75-\mathrm{v})] \mathrm{GL}[1-(\mathrm{B} / \mathrm{L})]$} \\
\hline Rocking(about longitudinal) & {$[\mathrm{G} /(1-\mathrm{v})]_{\mathrm{bx}}{ }_{\mathrm{bx}}^{0.75}(\mathrm{~L} / \mathrm{B})^{0.25}[2.4+0.5(\mathrm{~B} / \mathrm{L})]$} \\
\hline Rocking (about lateral) & {$[3 \mathrm{G} /(1-\mathrm{v})]_{\mathrm{by}}{ }^{0.75}(\mathrm{~L} / \mathrm{B})^{0.15}$} \\
\hline Torsion & {$\left[\left(3.5 \mathrm{GI}_{6 z}{ }^{0.75}\right)(\mathrm{B} / \mathrm{L})^{0.4}\left(\mathrm{I}_{6 z} / \mathrm{B}^{4}\right)^{0.2}\right]$} \\
\hline
\end{tabular}

Table 3.1.2.a Equivalent spring stiffness

\begin{tabular}{|c|c|}
\hline Degrees of freedom & Stiffness at surface of foundation \\
\hline Translation along $\mathrm{x}$-axis & $\mathrm{K}_{\mathrm{Lus}}=\left\{\mathrm{GB} /(2-\mathrm{v})\left[6.8(\mathrm{~L} / \mathrm{B})^{0.65}+2.4\right]\right\}$ \\
\hline Translation along y-axis & $\mathrm{K}_{\mathrm{y}, \mathrm{sx}}=\left\{\mathrm{GB} /(2-\mathrm{v})\left[6.8(\mathrm{~L} / \mathrm{B})^{0.65}+0.8(\mathrm{~L} / \mathrm{B})+1.6\right]\right\}$ \\
\hline Translation along $z$-axis & $\mathrm{K}_{\mathrm{z}, \mathrm{sx}}=\left\{\mathrm{GB} /(1-\mathrm{v})\left[3.1(\mathrm{~L} / \mathrm{B})^{0.75}+1.6\right]\right\}$ \\
\hline Rocking about $\mathrm{x}$ - axis & $\mathrm{K}_{\mathrm{axux}}=\left\{\mathrm{GB}^{3} /(1-\mathrm{v})[3.2(\mathrm{~L} / \mathrm{B})+0.8]\right\}$ \\
\hline Rocking about $y$ - axis & $\mathrm{K}_{\mathrm{yy}, \mathrm{sx}}=\left\{\mathrm{GB}^{3} /(1-\mathrm{v})\left[3.73(\mathrm{~L} / \mathrm{B})^{24}+0.27\right]\right\}$ \\
\hline Torsion about $\mathrm{z}$-axis & $\mathrm{K}_{2 x, \mathrm{sx} x}=\left\{\mathrm{GB}^{3}\left[4.25(\mathrm{~L} / \mathrm{B})^{245}+4.06\right]\right\}$ \\
\hline
\end{tabular}

Table 3.1.2.c Embedment correction factor

\begin{tabular}{|l|l|}
\hline Degrees of freedom & Embedment correction factor \\
\hline Translation along x- axis & $\mathrm{n}_{\mathrm{x}}=\left\{1+\left[0.33+(1.34 /(1+(\mathrm{L} / \mathrm{B}))](\mathrm{D} / \mathrm{B})^{0.8}\right\}\right.$ \\
\hline Translation along y- axis & $\mathrm{n}_{\mathrm{y}}=\left\{1+\left[0.33+(1.34 /(1+(\mathrm{L} / \mathrm{B}))](\mathrm{D} / \mathrm{B})^{0.8}\right\}\right.$ \\
\hline Translation along z- axis & $\mathrm{n}_{\mathrm{z}}=\left\{1+[0.25+(0.25 /(\mathrm{L} / \mathrm{B}))](\mathrm{D} / \mathrm{B})^{0.8}\right.$ \\
\hline Rocking about $\mathrm{x}$ - axis & $\mathrm{\eta}_{\mathrm{zx}}=\left\{1+(\mathrm{D} / \mathrm{B})+[1.6 /(0.35+(\mathrm{L} / \mathrm{B}))](\mathrm{D} / \mathrm{B})^{2}\right\}$ \\
\hline Rocking about y- axis & $\mathrm{n}_{\mathrm{yy}}=\left\{1+(\mathrm{D} / \mathrm{B})+\left[1.6 /\left(0.35+(\mathrm{L} / \mathrm{B})^{4}\right)\right](\mathrm{D} / \mathrm{B})^{2}\right\}$ \\
\hline Rocking about $\mathrm{z}$ - axis & $\mathrm{n}_{z z}=\left\{1+[1.3+(1.32 /(\mathrm{L} / \mathrm{B}))](\mathrm{D} / \mathrm{B})^{0.9}\right\}$ \\
\hline
\end{tabular}

\subsection{Superstructure modelling}

Models of 4, 8, 12, storied buildings of regular and irregular models are analyzed using ETABS. Irregularities considered are Diaphragm, Mass, Stiffness, Reentrant corner according to IS 1893(part I)-2002.Building configurations properties considered in the present work are summarized below.

\subsubsection{Building Specification}

Height of each storey $=3 \mathrm{~m}$

Plan dimension: $12 \mathrm{X} 12 \mathrm{~m}$

Height of bottom storey for stiffness irregular:7.5m

Height of bottom storey(Remaining models): $4.5 \mathrm{~m}$

Size of beams: $0.2 \mathrm{mX} 0.45 \mathrm{~m}$

Size of columns: $0.45 \mathrm{mX} 0.75 \mathrm{~m}$

Size of slab: $0.15 \mathrm{~m}$

Width of brick infill wall: $0.2 \mathrm{~m}$

Height of parapet wall: $1 \mathrm{~m}$

Unit weight of Brick work: $20 \mathrm{KN} / \mathrm{m}^{3}$

Poisson's ratio of concrete: 0.2

Poisson's ratio of steel: 0.3

Concrete grade: M30

Steel grade: $\mathrm{Fe} 415$

Concrete elastic modulus: $2.5 \times 10^{7} \mathrm{KN} / \mathrm{m}^{2}$

Steel elastic modulus: $2 \times 10^{8} \mathrm{KN} / \mathrm{m}^{2}$

Damping:0.05

Seismic zone :IV (Severe)

Zone factor : 0.24

Importance factor : 1

Response reduction factor : 5

Footing type: Isolated footing for all models

Depth of footing $: 1.5 \mathrm{~m}$

Live load on top floors: $1.5 \mathrm{KN} / \mathrm{m}^{2}$

Live load on mass irregular at middle floor of

$4,8,12$, storey is: $7 \mathrm{KN} / \mathrm{m}^{2}$

Live load on remaining floors: $3 \mathrm{KN} / \mathrm{m}^{2}$

Wall load: $10.2 \mathrm{KN} / \mathrm{m}$

Parapet wall load: $4 \mathrm{KN} / \mathrm{m}$

Table 3.1.2.b Stiffness at surface of foundations

Volume 5 Issue 6, June 2016 www.ijsr.net 


\section{International Journal of Science and Research (IJSR) \\ ISSN (Online): 2319-7064}

Index Copernicus Value (2013): 6.14 | Impact Factor (2015): 6.391
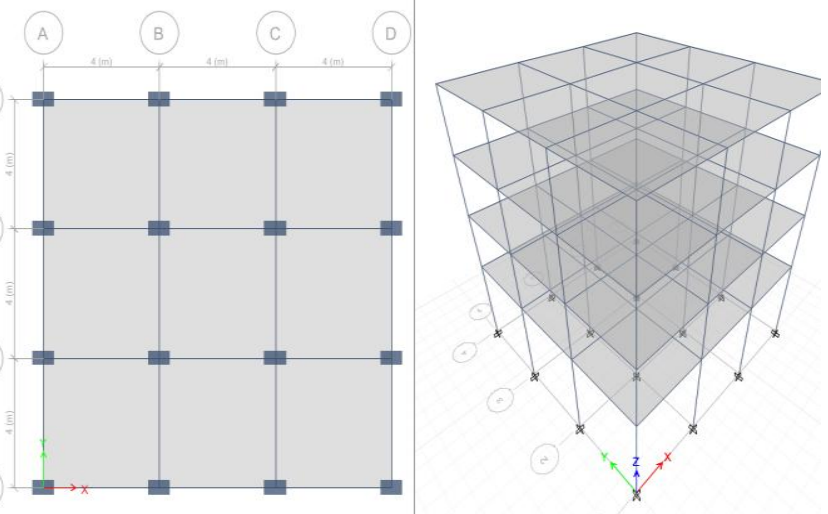

Figure 3.2.1(a): Regular 4 storey model (RF)
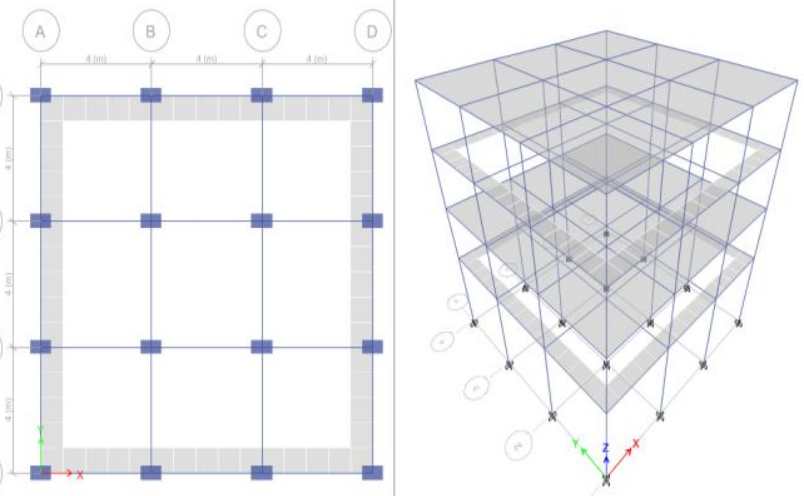

Figure 3.2.1(b): Four Storey diaphragm irregular model (DF)
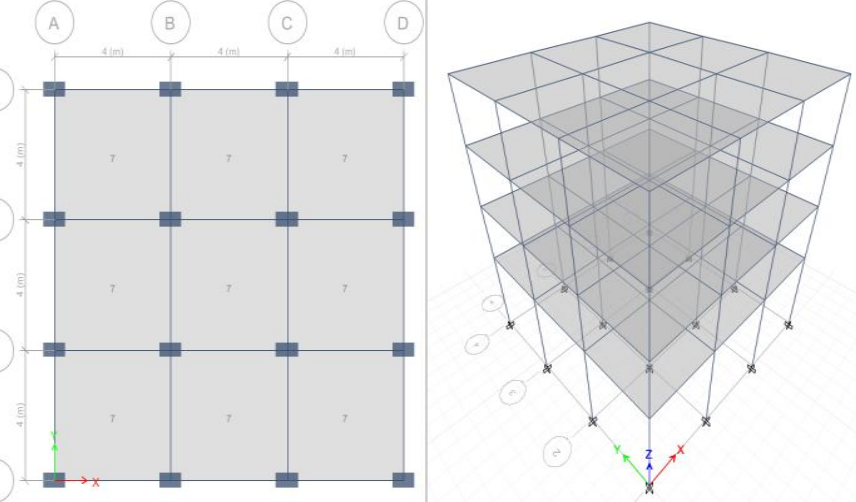

Figure 3.2.1(c): Four story building Mass irregular at $2^{\text {nd }}$ floor(MF)
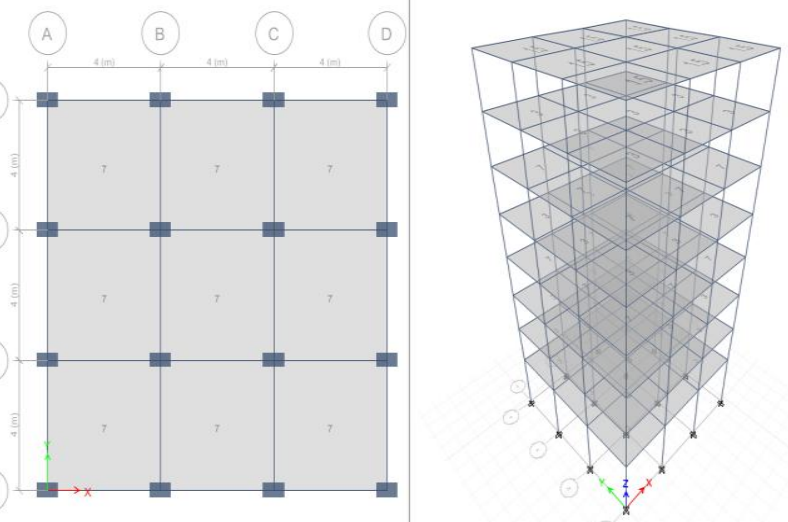

Figure 3.2.1(d): Eight storey building mass irregular at $4^{\text {th }}$ floor
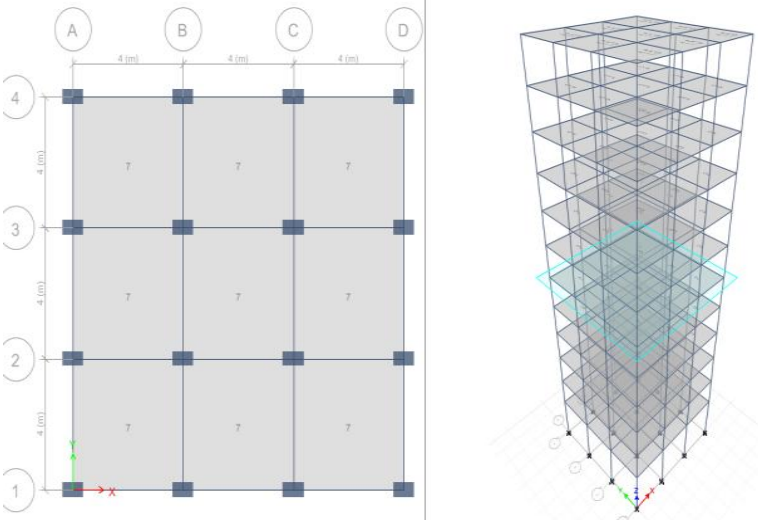

Figure 3.2.1 (e): Twelve storey building mass irregular at $6^{\text {th }}$ floor

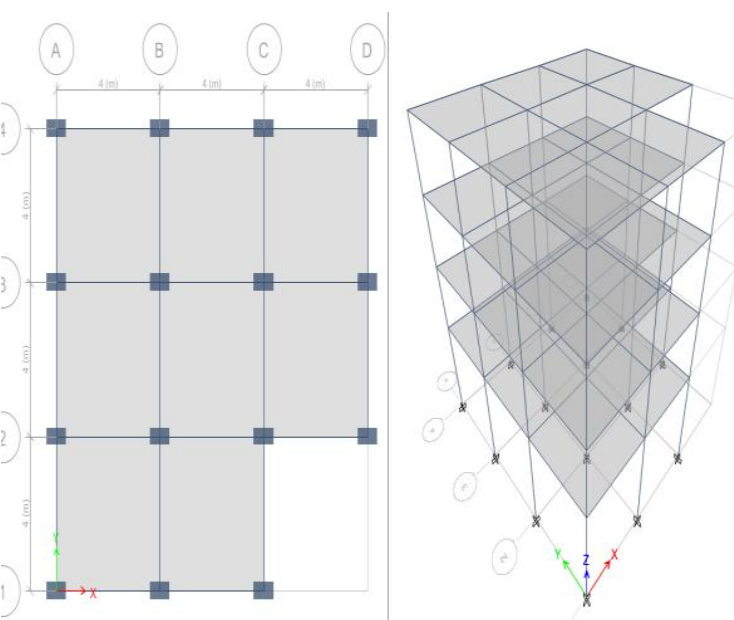

Figure 3.2.1(f): Reentrant corner in 4 storey model (REF)

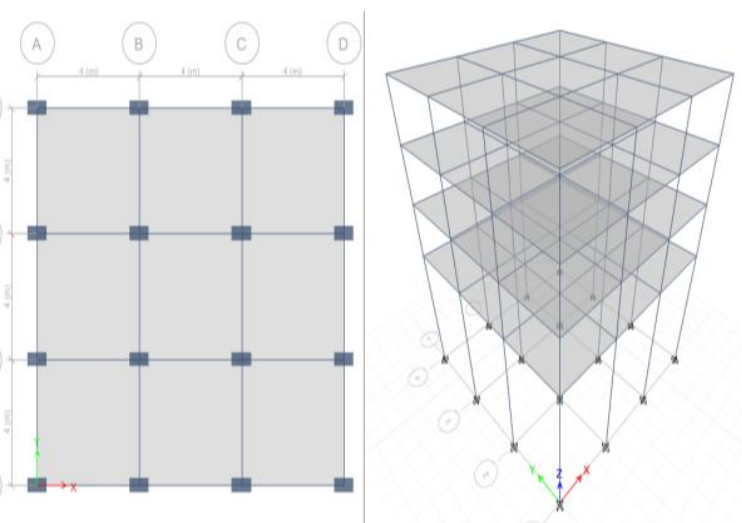

Figure 3.2.1(g): Stiffness irregularity of 4 storey model(SF)

\section{Volume 5 Issue 6, June 2016} www.ijsr.net

Licensed Under Creative Commons Attribution CC BY 


\section{International Journal of Science and Research (IJSR) \\ ISSN (Online): 2319-7064}

Index Copernicus Value (2013): 6.14 | Impact Factor (2015): 6.391

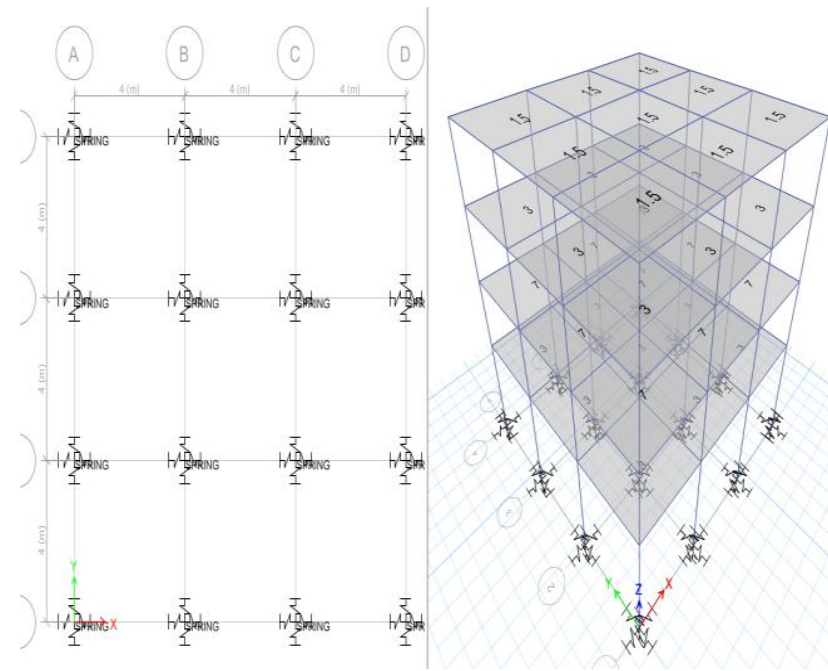

Figure 3.2.1(f): Springs assigned to CG of footing base for SSI

\section{Results and Discussions}

The present study attempts to evaluate the seismic response of special moment resisting framed regular and irregular building with rigid and flexible foundation.

Behavior of framed building with different heights on different soil types (hard, medium, soft) also studied.

Linear response spectrum analysis is carried out by ETABS to evaluate the earthquake response of 4,8,12 storeyed regular and irregular structures with and without soil structure interaction under different soil types. Base shear, natural period, maximum displacements are evaluated for all model types.

4,8,12 storey frames are analyzed for dead load, live load, seismic loads with and without soil structure interaction for different soil types. For flexible foundation modelling spring values are calculated for different types of soil, assigned to models to obtain the results. SSI models of Regular model, Diaphragm irregular model SSI, Mass irregular model, Reentrant irregular model, Stiffness irregular model are named as RFL, DFL, MFL, REFL, SFL respectively. Results are shown in below figures and tables

\subsection{Natural period $(T)$}

Time period mainly depends on the mass and flexibility of building. Below figures and tables shows the variation of natural period in soft, medium, hard soil types.

Table 4.1 (a): Natural period values in soft soil

\begin{tabular}{|l|l|l|l|l|l|l|l|l|l|l|}
\hline Storey & RF & RFL & DF & DFL & MF & MFL & REF & REFL & STF & STFL \\
\hline 4 & 0.61 & 0.78 & 0.58 & 0.76 & 0.64 & 0.78 & 0.63 & 0.78 & 1 & 1.17 \\
\hline 8 & 1.14 & 1.5 & 1.01 & 1.48 & 1.26 & 1.50 & 1.25 & 1.51 & 1.67 & 1.93 \\
\hline 12 & 1.76 & 2.1 & 1.72 & 2.08 & 1.89 & 2.30 & 1.89 & 2.33 & 2.33 & 2.74 \\
\hline
\end{tabular}

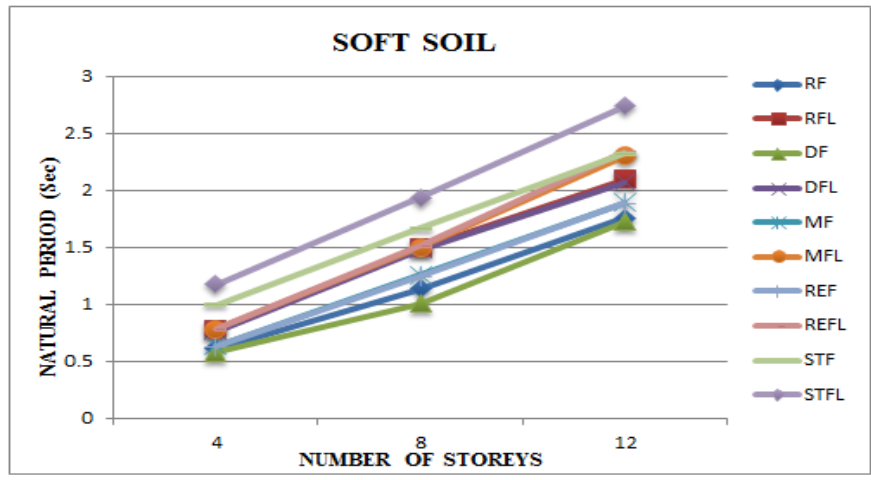

Figure 4.1 (a): Natural period variation in soft soil

Table 4.1 (b): Natural period values in medium soil \begin{tabular}{|l|l|l|l|l|l|l|l|l|l|l|}
\hline Storey & RF & RFL & DF & DFL & MF & MFL & REF & REFL & STF & STFL \\
\hline
\end{tabular} \begin{tabular}{|l|l|l|l|l|l|l|l|l|l|l|}
\hline 4 & 0.61 & 0.74 & 0.58 & 0.73 & 0.64 & 0.75 & 0.63 & 0.75 & 1 & 1.15 \\
\hline
\end{tabular}

\begin{tabular}{|l|l|l|l|l|l|l|l|l|l|l|}
\hline 8 & 1.14 & 1.43 & 1.01 & 1.41 & 1.26 & 1.44 & 1.25 & 1.44 & 1.67 & 1.87 \\
\hline 12 & 1.76 & 1.93 & 1.73 & 1.87 & 1.897 & 2.17 & 1.89 & 2.29 & 2.33 & 2.63 \\
\hline
\end{tabular}

\begin{tabular}{|l|l|l|l|l|l|l|l|l|l|l|}
\hline 12 & 1.76 & 1.93 & 1.73 & 1.87 & 1.897 & 2.17 & 1.89 & 2.29 & 2.33 & 2.63 \\
\hline
\end{tabular}

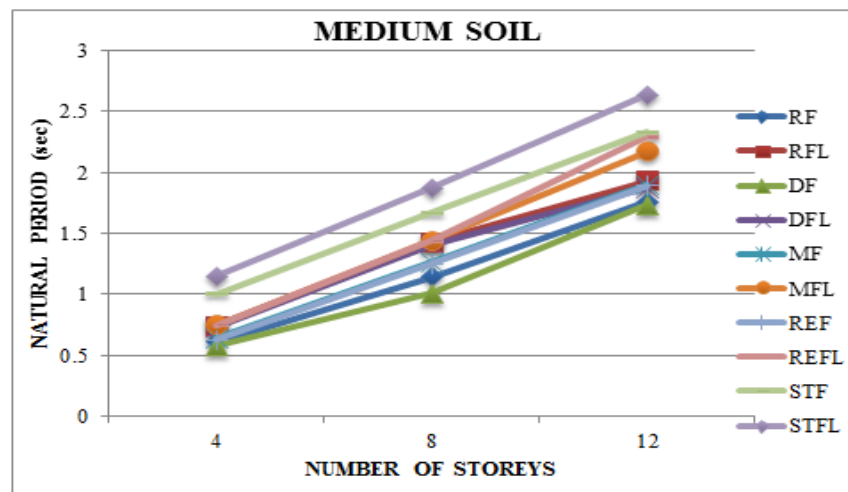

Figure 4.1(b): Natural period variation in medium soil

Table 4.1(c): Natural period values in hard soil

\begin{tabular}{|l|l|l|l|l|l|l|l|l|l|l|}
\hline Storey & RF & RFL & DF & DFL & MF & MFL & REF & REFL & STF & STFL \\
\hline 4 & 0.61 & 0.72 & 0.58 & 0.71 & 0.64 & 0.74 & 0.63 & 0.74 & 1 & 1.13 \\
\hline 8 & 1.14 & 1.41 & 1.01 & 1.4 & 1.26 & 1.45 & 1.25 & 1.42 & 1.67 & 1.78 \\
\hline 12 & 1.76 & 1.81 & 1.73 & 1.73 & 1.9 & 2.12 & 1.89 & 2.25 & 2.33 & 2.5 \\
\hline
\end{tabular}

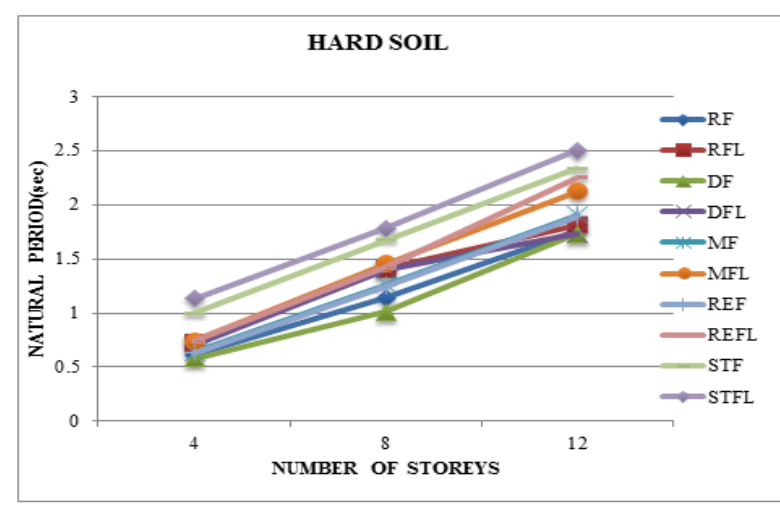

Figure 4.1(c): Natural period variation in hard soil

\subsection{Base shear $(V)$}

Seismic force at building base is known as base shear, in the current study base shear decreases for the input of SSI effect due to increased natural period of building. Below figures

\section{Volume 5 Issue 6, June 2016 www.ijsr.net}




\section{International Journal of Science and Research (IJSR) \\ ISSN (Online): 2319-7064}

Index Copernicus Value (2013): 6.14 | Impact Factor (2015): 6.391

and tables shows values and variation of base shear in all soil types.

Table 4.2.a: Base shear values in soft soil

\begin{tabular}{|l|l|l|l|l|l|l|l|l|l|l|}
\hline Storeys & RF & RFL & DF & DFL & MF & MFL & REF & REFL & STF & STFL \\
\hline 4 & 525.6 & 502.8 & 454.2 & 435.3 & 534.2 & 513.3 & 478.3 & 462.6 & 480.2 & 366.9 \\
\hline 8 & 606.9 & 513.8 & 572.5 & 449.4 & 634.9 & 539.3 & 595.3 & 506.3 & 544.1 & 442.9 \\
\hline 12 & 657.1 & 521.7 & 587 & 456.9 & 663.7 & 560.9 & 594.3 & 471 & 565.7 & 457 \\
\hline
\end{tabular}

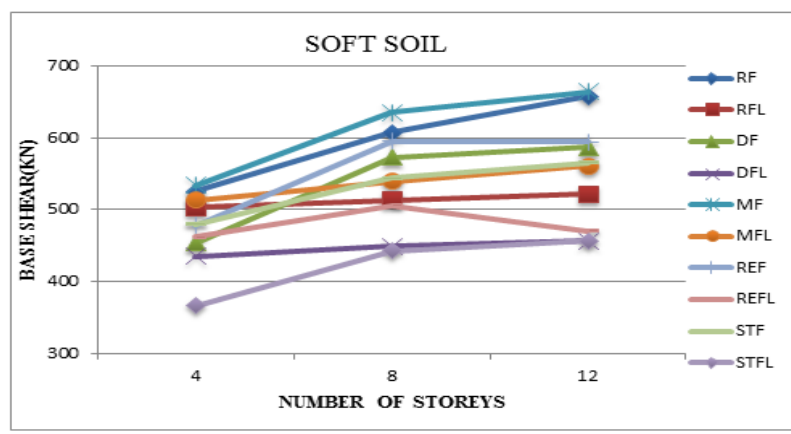

Figure 4.2 (a): Base shear variation in soft soil

Table 4.2.b: Base shear values in medium soil

\begin{tabular}{|l|l|l|l|l|l|l|l|l|l|l|}
\hline Storey & RF & RFL & DF & DFL & MF & MFL & REF & REFL & STF & STFL \\
\hline 4 & 452.6 & 423.1 & 401.3 & 367.4 & 482.7 & 432.4 & 434.5 & 386.7 & 357.6 & 306.6 \\
\hline 8 & 513.1 & 457.3 & 438.2 & 382.1 & 526.5 & 467 & 456.2 & 386.4 & 443.1 & 374.4 \\
\hline 12 & 571.8 & 479.7 & 478.1 & 397.4 & 582.3 & 492.8 & 484 & 410.1 & 460.7 & 394.4 \\
\hline
\end{tabular}

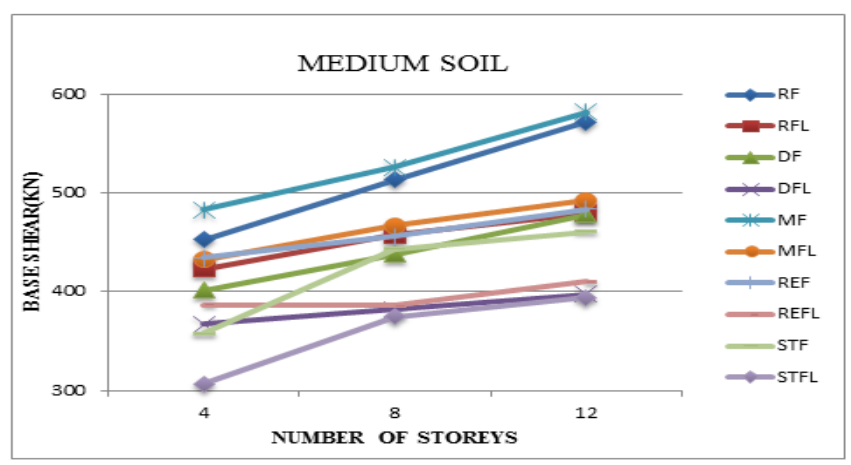

Figure 4.2.b:Base shear variation in medium soil

Table 4.2.c: Base shear values in hard soil

\begin{tabular}{|l|l|l|l|l|l|l|l|l|l|l|}
\hline Storey & RF & RFL & DF & DFL & MF & MFL & REF & REFL & STF & STFL \\
\hline 4 & 332.7 & 302.4 & 322.5 & 272.3 & 375 & 307.3 & 322.6 & 278.2 & 287.5 & 216 \\
\hline 8 & 345.3 & 312 & 338.9 & 287.9 & 389.8 & 340.6 & 315 & 308.5 & 325.8 & 273.6 \\
\hline 12 & 369.4 & 325.2 & 357.5 & 284.3 & 401.4 & 340.6 & 355.9 & 311.6 & 338.7 & 286.6 \\
\hline
\end{tabular}

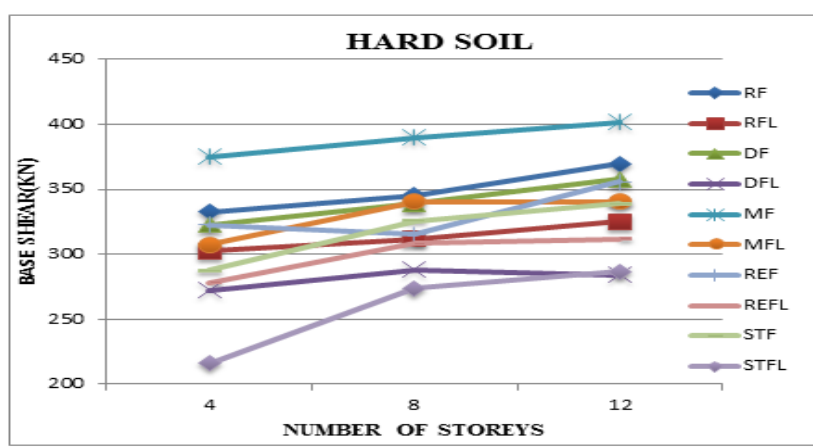

Figure 4.2.c:Base shear variation in hard soil

\subsection{Maximum displacement $(\Delta \max )$}

Maximum displacement is the maximum displace of storey at any level maximum displacement occurs at top storeys. Below figures and tables shows the variation and values of maximum displacement in soft, medium, hard soil.

Table 4.3.a: Maximum displacement values in soft soil

\begin{tabular}{|l|l|l|l|l|l|l|l|l|l|l|}
\hline Storey & RF & RFL & DF & DFL & MF & MFL & REF & REFL & STF & STFL \\
\hline 4 & 8.3 & 15.1 & 7.1 & 14.6 & 10.5 & 16.8 & 10.2 & 16.3 & 15.8 & 20 \\
\hline 8 & 28.4 & 36.6 & 26.6 & 35.7 & 29.9 & 37.6 & 29.4 & 36.8 & 32 & 40.2 \\
\hline 12 & 46.2 & 61.2 & 45.4 & 60.7 & 47.5 & 61.874 & 46.4 & 62.9 & 50 & 64.4 \\
\hline
\end{tabular}

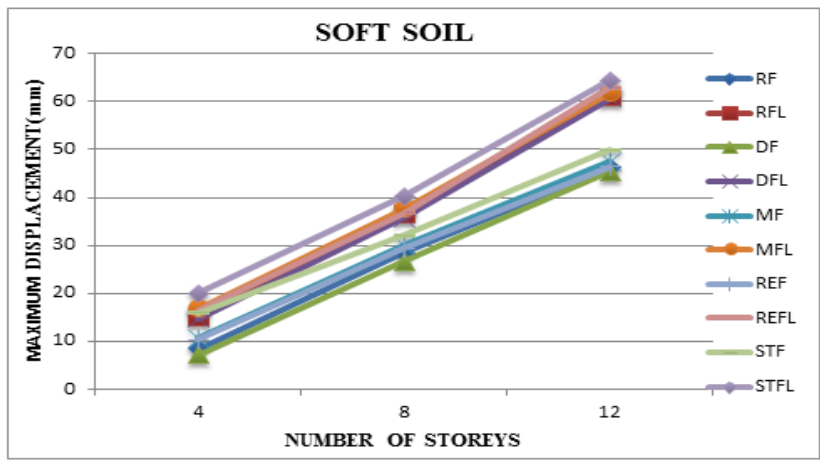

Figure 4.3.a:Maximum displacement variation in soft soil

Table 4.3.b: Maximum displacement values in medium soil

\begin{tabular}{|l|l|l|l|l|l|l|l|l|l|l|}
\hline Storey & RF & RFL & DF & DFL & MF & MFL & REF & REFL & STF & STFL \\
\hline 4 & 8.1 & 13.1 & 6.42 & 12.8 & 9.2 & 14.7 & 8.2 & 14.6 & 11.4 & 15.7 \\
\hline 8 & 23.3 & 26.6 & 22.6 & 25.8 & 25.4 & 28.8 & 23.9 & 27.3 & 26.1 & 30.8 \\
\hline 12 & 37.4 & 44.5 & 36.2 & 43.3 & 39.7 & 46.1 & 37.7 & 44.7 & 40.3 & 48.4 \\
\hline
\end{tabular}

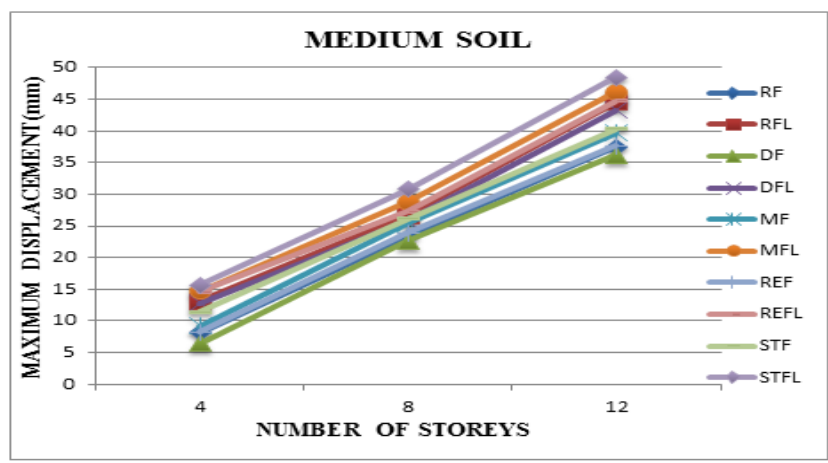

Figure 4.3.b:Maximum displacement variation in medium soil

Table 4.3.c: Maximum displacement values in hard soil

\begin{tabular}{|c|l|l|l|l|l|l|l|l|l|l|}
\hline Storey & RF & RFL & DF & DFL & MF & MFL & REF & REFL & STF & STFL \\
\hline 4 & 7.7 & 8.2 & 7.5 & 8.1 & 8.1 & 9.8 & 7.9 & 9.4 & 9.5 & 11.7 \\
\hline 8 & 17.6 & 19.5 & 17.2 & 19.4 & 18 & 20.7 & 17.7 & 19.6 & 19.1 & 22.3 \\
\hline 12 & 26 & 32.3 & 27.3 & 32 & 28.5 & 33.5 & 27.5 & 32.4 & 29.6 & 35.1 \\
\hline
\end{tabular}

\section{Volume 5 Issue 6, June 2016 www.ijsr.net}

Licensed Under Creative Commons Attribution CC BY 


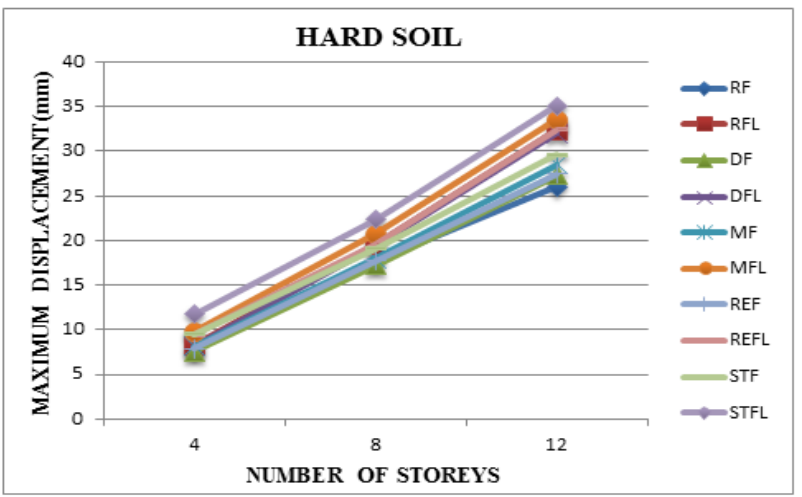

Figure 4.3 (c): Maximum displacement variation in hard soil

\section{Conclusions}

From the above results for all different model cases leads to the following broad conclusions.

- From this study shows that, natural period depends on building configuration that is as the height of the building increases time period increased and due to irregularity also natural period increased.

- Base shear varies indirectly with natural period in this study due to increase in natural period for SSI incorporated buildings base shear is reduced.

- Natural period remains same in conventional analysis for different soil types, it increased with increase in soil flexibility for real SSI effect.

- Plan irregular buildings are not much vulnerable compared to vertical irregular buildings. In this study natural period is more for the mass and stiffness irregular building with SSI inclusion compared to plan irregular building.

- Due to reduction of soil stiffness from hard to soft natural period is increased for soft soil.

- Maximum displacement increases with increase in soil flexibility, also as the building height increases from 4 to 12 storey maximum displacement is found to be more for building on soft soil.

- Maximum displacement also depends on structural type, for regular structure it is less than irregular building due to more pliability in irregular building.

- Due to increased natural period in irregular building which reduces the irregular building stiffness, and increases the inertial forces.

- From this study reveals that maximum displacement is more for stiffness irregular on soft soil with SSI.

- For all models with SSI the seismic response is more hence Soil interaction included models are more vulnerable compared to fixed base. Hence while designing tall structures for earthquake resistant design rather than using fixed base condition, substructure effect should be included to get exact response of building.

\subsection{Scope for future work}

1) Study of dynamic soil structure interaction with shallow foundation by time history analysis.

2) Study of dynamic soil structure interaction of irregular building under different zones.

3) By modeling soil in three dimension analysis also made.
4) Study of Soil nonlinear behavior by the inclusion of nonlinear springs.

5) This study also extended for tall structures and also different types of models.

6) This study also extended by providing raft and pile foundation.

\section{References}

[1] K Battacharya et al.,(2006) "Sesmic design aids for building incorporating soil flexibility effect".

[2] C.M Ravikumar et al.,(2012) "Effect of irregular configuration on seismic vulnerability of RC building, NIT surathkal.

[3] Jenifer Priyanka R M et al.,(2012) "Studies on soil structure interaction of multistoried building with rigid \& flexible base foundation,ISSN2250-2459.

[4] Jayalakshmi B R et al.,(2013) "Effect of soil flexibility on lateral natural period in RC framed buildings with shear wall,ISSN:2319-8753.

[5] Dr.Ragavendra singh et al.,(2014) "Seismic behavior of buildings having vertical irregularities",Vol-I, IISN:2349-655X.

[6] $\mathbf{N}$ suresh et al.,(2015) "Effect of relative stiffness on foundation to soil on interaction behavior of raft footing,SSRG-IJCE.

[7] J P Nadar et al.,(2015) "soil structure interaction of tall buildings", ICQUEST-2015.

[8] Mr.S.B.Magade,Prof. J P Patankar, "Effect of soil structure interaction on the dynamic behavior of buildings,IOSR-JMCE.

[9] Sachin Hosamani et al.,(2015) "Soil structure interaction of RC framed irregular building with shear walls,IRJET,e-ISSN:2395-0056.

[10] J E Bowles, "Foundation analysis and design", consulting engineer,peoria,Illinois.

[11] "Soil structure interacton for building structures", NIST GCR12-917-21, NEHRP consultents.

[12] Bryan Stafford Smith and Alex Coull, "Tall building structures analysis and design", McGillc University Montreal and University of Glasgow Scotlend.

[13] Parmalee R.A. and J.H.Wronkiewicz, "Seismic design of soil structure interaction systems", Journal of Structural Div, proceedings of the American Society of Civil Engineers, ST 10, Oct1971,pp -2503-2517.

[14] PrabhatKumarA.D.Pandey,andSharadSharma "Seismicsoil-structure interaction of buildings on hill slopes",Journalof Civiland StructuralEngineering, 2011.

[15] Kraus \& D. Dzakic, "Soil-structure interaction effects on seismic behaviour of reinforced concrete frames", JosipJurajStrossmayer University of Osijek, Faculty of Civil Engineering Osijek, Croatia

[16] SharbonyAdhikary, Yogendrasingh and D. K. Paul, "Modeling of soil -foundation - structure system", department of earthquake engineering IIT Roorkee.

[17] Wolf, J.P, Prentice Hall, Englewood Cliffs, N.J., 1985. "Soil- Structure Interaction".

[18] IS: 456-2000, "Code of Practice for Plain and Reinforced Concrete", Bureau of Indian Standards, New Delhi, India. 


\section{International Journal of Science and Research (IJSR) \\ ISSN (Online): 2319-7064}

Index Copernicus Value (2013): 6.14 | Impact Factor (2015): 6.391

[19] IS:1893 (Part 1)-2002 Criteria for Earthquake Resistant Design of Structures, part 1-General provisions and buildings, fifth revision, Bureau of Indian Standards, New Delhi, India

\section{Author Profile}

Mamathashree K S is PG student, pursuing M.Tech in structural Engineering at BGS Institute of Technology, BG Nagar.

Sanjay S J received the B.E.degree in civil engineering from Visvesvaraya University in 2010, and the M.Tech. Degree in CADSS from UBDTCE, Davangere in 2012 and also member of AMIE. Presently working as an Assistant Professor in BGSIT, B.G NAGAR

Volume 5 Issue 6, June 2016 www.ijsr.net 